\title{
Predictors for Unfavorable Early Outcomes in Elective Total Hip Arthroplasty: Does Extreme Body Mass Index Matter?
}

\author{
Chun-Yu Hung $\mathbb{D}^{1}{ }^{1}$ Chih-Hsiang Chang, ${ }^{1,2}$ Yu-Chih Lin, ${ }^{1,2}$ Shen-Hsun Lee, ${ }^{1,2}$ \\ Szu-Yuan Chen, ${ }^{1,2}$ and Pang-Hsin Hsieh $\mathbb{D}^{1,2}$ \\ ${ }^{1}$ Department of Orthopaedic Surgery, Chang Gung Memorial Hospital, Linkou, Taiwan \\ ${ }^{2}$ Chang Gung University, Taoyuan, Taiwan \\ Correspondence should be addressed to Pang-Hsin Hsieh; hsieh2634@gmail.com
}

Received 16 May 2019; Revised 11 August 2019; Accepted 19 September 2019; Published 7 October 2019

Academic Editor: Alberto Grassi

Copyright (c) 2019 Chun-Yu Hung et al. This is an open access article distributed under the Creative Commons Attribution License, which permits unrestricted use, distribution, and reproduction in any medium, provided the original work is properly cited.

\begin{abstract}
Background. Studies of previous cohorts have demonstrated a controversial association between extreme body mass index (BMI) and complication rates following total hip arthroplasty (THA). The purpose of this study was to compare 30-day perioperative complications in underweight (BMI $\left.<18.50 \mathrm{~kg} / \mathrm{m}^{2}\right)$, normal-weight (BMI $18.50-24.99 \mathrm{~kg} / \mathrm{m}^{2}$ ), overweight (BMI $25.00-29.99 \mathrm{~kg} /$ $\mathrm{m}^{2}$ ), class I obesity (BMI $30.00-34.99 \mathrm{~kg} / \mathrm{m}^{2}$ ), and morbidly obese (BMI $\geq 35.00 \mathrm{~kg} / \mathrm{m}^{2}$ ) groups. Methods. We performed a cohort study including patients who underwent unilateral primary THA by a single surgeon between January 2010 and December 2015 at our institution. We assessed 30-day complications, operation time, operative blood loss, and length of hospital stay. Results. We identified 1565 primary THAs that were performed in patients with varying BMI levels. Compared with the normal-weight patients, the morbidly obese group had a higher 30 -day complication rate ( $8.9 \%$ vs. $2.4 \%)$, longer operative time (79 minutes vs. 70 minutes), and more blood loss $(376 \mathrm{~mL}$ vs. $302 \mathrm{~mL})$. Underweight patients did not present any 30 -day complications, and there were no differences among underweight and normal-weight patients regarding complication rates, operative time, or blood loss. The mean length of hospital stay was comparable among the different BMI groups. In the multivariate regression model, higher BMI was not associated with a higher risk of 30-day complications. Independent risk factors for 30-day complications were advanced age, prolonged operative time, and cardiovascular comorbidities. Conclusion. Although increased operative time, blood loss, and perioperative complications were seen in the morbidly obese patients, BMI alone was not an independent risk factor for a higher 30-day complication rate. Therefore, our data suggest clinicians should make elderly patients aware of increased 30-day complications before the procedure, particularly those with cardiovascular comorbidities. Withholding THA solely on the basis of BMI is not justified.
\end{abstract}

\section{Introduction}

Total hip arthroplasty (THA) reduces pain and improves function and quality of life in the great majority of patients with a severely damaged arthritic hip [1-3]. In recent decades, the demand for THA has increased worldwide, accounting for a large share of the national health expenditure $[4,5]$. In Taiwan, the number of THAs performed is projected to increase by $69.7 \%$ in 2030 compared to 2005 [6].

Obesity continues to be a troublesome public health issue because of the established health risks and substantial increase in prevalence [7]. A positive association between obesity and hip osteoarthritis has been studied intensively [8-11]. Rising levels of obesity coupled with projected growing demand for THA present a challenging problem for orthopedic surgeons [12]. Some studies have shown that obese patients are associated with a higher rate of perioperative complications following THA, including dislocations, deep wound infections, and venous thromboembolic disease [13-15]. Furthermore, obese patients are associated with longer hospital stays and higher costs than the general population $[16,17]$. Conversely, other studies have not found any differences with regard to the above complications [18-20]. 
Apart from obese patients, underweight patients undergoing THA are also an issue within the arthroplasty community; however, they have been largely overlooked and understudied. Compared with normal-weight patients, underweight patients may incur a higher rate of postoperative dislocation, infection, and cardiac complications $[21,22]$. However, a recent cohort study presents contradictory results and reports that there are no increased rates of infectious or medical complications in underweight patients undergoing THA [23].

With this conflicting background, we undertook a large, retrospective study in a high-volume referral center to examine whether the clinical outcomes of patients with extreme BMI levels differed from those of normal-weight patients.

\section{Patients and Methods}

2.1. Study Design. We retrospectively studied prospectively gathered data, analyzing the relationships between patient BMI and perioperative complications in primary THAs. The study protocol was approved by the Institutional Review Board of the Chang Gung Memorial Hospital. All THAs took place at a single institution, and a single experienced surgeon who performed more than 300 primary THAs per year during the study period participated in all of the operations. Our center is a tertiary referral hospital located in north Taiwan, treating 600 new cases of primary THA per year.

Demographic data were collected including age, sex, body mass index (BMI), surgical approach, etiology of hip pathology, and comorbidities. We classified patients using the World Health Organization definitions for BMI, as underweight (BMI $<18.50 \mathrm{~kg} / \mathrm{m}^{2}$ ), healthy (BMI 18.50 $24.99 \mathrm{~kg} / \mathrm{m}^{2}$ ), overweight (BMI $25.00-29.99 \mathrm{~kg} / \mathrm{m}^{2}$ ), class I obese (BMI $30.00-34.99 \mathrm{~kg} / \mathrm{m}^{2}$ ), and morbidly obese $\left(\geq 35.00 \mathrm{~kg} / \mathrm{m}^{2}\right)$ groups [24]. At our institution, it is our practice not to refuse THA because of obesity.

All complications that occurred during the hospital stay and within a 30-day postoperative period were identified. Complications were then divided into surgery-related and surgery-unrelated categories. Surgery-related complications included intraoperative periprosthetic fracture, nerve injury, superficial wound infection, deep wound infection, dislocation, and deep vein thrombosis. Surgery-unrelated complications included periprosthetic fractures resulting from postoperative fall, acute renal failure, stroke, and readmission to hospital for any reason other than surgery-related complications during the first 30 days after THA. Reasons for readmission and the relationship with the index THA were recorded, while we excluded planned readmissions, such as scheduled spine surgery or contralateral side THA.

2.2. Eligibility. From January 2010 to December 2015, the results of 1987 consecutive primary THAs (in 1790 patients) performed by the senior surgeon were examined. We excluded patients who had coagulation abnormalities, radiation-induced femoral head necrosis, bilateral THA on the same day, and THA for acute fracture of the hip. For patients who received bilateral sequential THA during the period, data were recorded only for the first procedure. Overall, 1565 unilateral primary THAs in 1565 patients were eligible for inclusion in the study.

2.3. Surgical Technique. All enrolled patients received general anesthesia and orotracheal intubation. All surgical procedures were performed by a single surgeon using the transgluteal surgical approach, modified from the direct lateral approach described by Hardinge [25], and were the same as the technique described by Frndak et al. [26]. The prosthesis used in all patients was the Trilogy Acetabular Cup and VerSys Fiber Metal Taper Stem (Zimmer, Warsaw, IN, USA). The fixation of the cementless THA components was achieved primarily by the press-fit technique. Augmented screw insertion for supplemental acetabular cup fixation was not routine but was used when necessary as judged by the treating surgeon.

2.4. Postoperative Care. The postoperative care and rehabilitation protocol were standardized for all patients and included venous thromboembolic prophylaxis and intravenous antibiotics. Postoperatively, patients were allowed to mobilize to full weight-bearing movements as tolerated, using a walker in the first 4 weeks or for as long as they thought was necessary. Antibiotic prophylaxis was given routinely for 1 day, while anticoagulant prophylaxis continued for up to 35 days after surgery in the absence of contraindications [27].

2.5. Outcome Assessment. The primary outcome measures were 30-day complication rate, including surgery-related and surgery-unrelated complications.

2.6. Data Analysis. All analyses were performed using the SPSS statistical software, version 22.0 (SPSS Inc, Chicago, IL, USA). For the normally distributed numerical outcome data, one-way analysis of variance (ANOVA) and Scheffe post hoc tests were used for between-group comparisons. The Fisher exact test and chi-squared test were used to compare categorical data among the groups. The multivariate regression model included patient demographics, comorbidity, and operative variables with a univariate comparison $p$ value of $<0.05$. Cofounders such as age, gender, cardiovascular comorbidities, and operation time were included in the regression model to investigate the relationship between the outcomes and BMI. The significance level was set at $p<0.05$ for all univariate and multivariate analyses.

\section{Results}

3.1. Patient Characteristics. In total, 1565 primary THAs were carried out in 1565 patients who met the inclusion criteria. All 1565 patients with 1565 THAs were followed up for at least one month. The demographic and preoperative details of all patients are shown in Table 1. 
TABLE 1: Demographics, preoperative comorbidity, and operative variables in different BMI groups.

\begin{tabular}{|c|c|c|c|c|c|c|}
\hline BMI & $<18.5$ & $18.5-24.99$ & $25-29.99$ & $30-34.99$ & $>35$ & $p$ value \\
\hline Number of patients & 56 & 697 & 609 & 158 & 45 & \\
\hline Mean BMI (SD), $\mathrm{kg} / \mathrm{m}^{2}$ & $17.35(1.28)$ & $22.57(1.66)$ & $27.21(1.41)$ & $31.95(1.29)$ & $37.60(2.94)$ & $<0.001^{\mathrm{a}}$ \\
\hline Mean age (SD, range), y & $47.0(16.8,22-83)$ & $54.6(14.6,16-91)$ & $57.5(13.2,15-87)$ & $56.0(14.0,21-87)$ & $57.2(12.2,26-77)$ & $<0.001^{\mathrm{a}}$ \\
\hline $\begin{array}{l}\text { Sex, } n(\%) \\
\text { Male } \\
\text { Female } \\
\end{array}$ & $\begin{array}{l}23(41.1) \\
33(58.9) \\
\end{array}$ & $\begin{array}{l}289(41.5) \\
408(58.5) \\
\end{array}$ & $\begin{array}{l}327(53.7) \\
282(46.3) \\
\end{array}$ & $\begin{array}{l}80(50.6) \\
78(49.4) \\
\end{array}$ & $\begin{array}{l}16(35.6) \\
29(64.4) \\
\end{array}$ & $<0.001^{\mathrm{a}}$ \\
\hline $\begin{array}{l}\text { Pathology, } n(\%) \\
\text { OA } \\
\text { Osteonecrosis } \\
\text { Inflammatory } \\
\text { Dysplasia } \\
\text { Perthes disease } \\
\text { FAI } \\
\text { OA hip secondary to } \\
\text { childhood septic hip }\end{array}$ & $\begin{array}{c}3(5.4) \\
35(62.5) \\
11(19.6) \\
7(12.5) \\
0 \\
0 \\
0\end{array}$ & $\begin{aligned} 110 & (15.8) \\
317 & (45.5) \\
34 & (4.9) \\
212 & (30.4) \\
10 & (1.4) \\
9 & (1.3) \\
5 & (0.7)\end{aligned}$ & $\begin{aligned} 135 & (22.2) \\
215 & (35.3) \\
32 & (5.3) \\
192 & (31.5) \\
13 & (2.1) \\
17 & (2.8) \\
5 & (0.8)\end{aligned}$ & $\begin{aligned} 24 & (15.2) \\
66 & (41.8) \\
6 & (3.8) \\
57 & (36.1) \\
2 & (1.3) \\
3 & (1.8) \\
& 0\end{aligned}$ & $\begin{aligned} & 7(15.6) \\
& 11(24.5) \\
& 2(4.4) \\
& 24(53.3) \\
& 0 \\
& 1 \\
& 1(2.2) \\
& 0\end{aligned}$ & \\
\hline $\begin{array}{l}\text { Fixation, } n(\%) \\
\text { Cemented } \\
\text { Hybrid } \\
\text { Cementless } \\
\end{array}$ & $\begin{array}{c}0 \\
0 \\
56(100) \\
\end{array}$ & $\begin{array}{c}1(0.1) \\
8(1.2) \\
688(98.7) \\
\end{array}$ & $\begin{array}{c}0 \\
2(0.3) \\
607(99.7) \\
\end{array}$ & $\begin{array}{c}0 \\
1(0.6) \\
157(99.4) \\
\end{array}$ & $\begin{array}{c}0 \\
0 \\
45(100) \\
\end{array}$ & 0.58 \\
\hline $\begin{array}{l}\text { ASA score } \\
1-2 \\
3-4 \\
\end{array}$ & $\begin{array}{l}45(80.4) \\
11(19.6) \\
\end{array}$ & $\begin{array}{l}536(77) \\
161(23) \\
\end{array}$ & $\begin{array}{l}498(81.8) \\
111(18.2) \\
\end{array}$ & $\begin{array}{c}119(75.3) \\
39(24.7)\end{array}$ & $\begin{array}{l}31(68.9) \\
14(31.1) \\
\end{array}$ & 0.07 \\
\hline $\begin{array}{l}\text { Comorbidity, } n(\%) \\
\text { Cardiovascular } \\
\text { comorbidities } \\
\text { Respiratory comorbidities } \\
\text { Diabetes }\end{array}$ & $\begin{array}{c}11(19.6) \\
10(17.9) \\
3(5.4)\end{array}$ & $\begin{array}{c}252(36.2) \\
104(14.9) \\
71(10.2)\end{array}$ & $\begin{array}{c}306(50.2) \\
82(13.5) \\
91(14.9)\end{array}$ & $\begin{array}{l}103(65.2) \\
26(16.5) \\
37(23.4)\end{array}$ & $\begin{array}{c}33(73.3) \\
9(20.0) \\
17(37.8)\end{array}$ & $\begin{array}{c}<0.001^{\mathrm{a}} \\
0.629 \\
<0.001^{\mathrm{a}}\end{array}$ \\
\hline
\end{tabular}

OA, osteoarthritis; FAI, femoroacetabular impingement; SD, standard deviation. ${ }^{\text {a}}$ Statistically significant difference $(p<0.05)$.

3.2. Operative Time. There was a significant difference in operation time (Table 2) among the groups. The mean operative time was longer $(p<0.001)$ for patients who were morbidity obese than for patients in the other four groups.

3.3. Blood Loss. The comparison of blood loss (Table 2) between the different BMI groups also showed a significant increase in the morbidly obese group with the mean of $376 \mathrm{~mL}$ (SD 186), with $302 \mathrm{~mL}$ (SD 132) in the normalweight group. There was no significant difference between the groups regarding the length of hospital stay (ANOVA, $p=0.531)$.

3.4. Complications. We observed an overall complication rate of $2.8 \%(n=44)$ in our series. The complications are listed in Table 3 . When stratified according to BMI, the complication rate was higher in morbidly obese patients. Overall, $0 \%$ of patients in the underweight group, $2.4 \%$ of patients in the normal-weight group, $3.1 \%$ of overweight patients, and $2.5 \%$ of class I obesity patients had complications, compared to $8.9 \%$ of morbidly obese patients.

Adjusted odds of overall complications among different BMI groups showed no significant differences after controlling confounding factors. Associations between individual complications and BMI categories were not examined in the multivariate logistic regression model, as individual complications occurred too infrequently. In contrast, longer operative time
(OR 1.02, 95\% CI 1.006-1.034, $p=0.006$ ), older age (OR 1.027, 95\% CI 1.001-1.054, $p=0.041)$, and cardiovascular comorbidities (OR 2.443, 95\% CI 1.162-5.132, $p=0.018$ ) were found to be associated with overall 30-day complications (Table 4).

The incidence of periprosthetic infection was higher in the morbidly obese group than in the other four groups: $0 \%$ $(n=0)$ for underweight patients, $0.14 \%(n=1)$ for normalweight patients, $0 \%(n=0)$ for overweight patients, and $0 \%$ $(n=0)$ for class I obesity patients, compared with $2.2 \%$ $(n=1)$ in morbidly obese patients.

The dislocation rate was $0.19 \%(n=3)$ in this investigation. Notably, 3 patients experienced dislocations on average 3 weeks following the index surgery and all occurred in the normal-weight patients. Two patients were treated with closed reduction successfully. One patient experienced recurrent dislocation and achieved stability after revision hip arthroplasty. There was no statistically significant difference in the dislocation rate between the groups.

\section{Discussion}

The obesity epidemic is becoming a worldwide phenomenon and has been identified as a national health problem [28, 29]. The prevalence of obesity has been increasing sharply in Taiwan over the past 20 years [30]. Due to the association of obesity with the development of osteoarthritis, the obese population will be at greater risk of total joint arthroplasty and comprise an everincreasing segment of the total joint arthroplasty population 
TABLE 2: Perioperative parameters.

\begin{tabular}{|c|c|c|c|c|c|c|c|}
\hline BMI & $<18.5$ & $18.50-24.99$ & $25-29.99$ & $30-34.99$ & $>35.00$ & $p$ value & $\begin{array}{l}\text { Post } \\
\text { hoc }\end{array}$ \\
\hline Number of patients & 56 & 697 & 609 & 158 & 45 & & \multirow{5}{*}{$\begin{array}{l}\text { B vs. E } \\
\text { C vs. E } \\
\text { A vs. E } \\
\text { B vs. E }\end{array}$} \\
\hline $\begin{array}{l}\text { Mean operative time ( } \mathrm{SD} \text {, } \\
\text { range), min }\end{array}$ & $\begin{array}{c}74.39(18.54 \\
44-118)\end{array}$ & $\begin{array}{c}69.82(17.59 \\
30-162)\end{array}$ & $\begin{array}{c}68.56(16.35 \\
42-160)\end{array}$ & $\begin{array}{c}73.02(18.59 \\
40-165)\end{array}$ & $\begin{array}{c}78.96(23.68 \\
47-163)\end{array}$ & $<0.001^{\mathrm{a}}$ & \\
\hline Mean blood loss (SD), mL & $261(148)$ & $302(132)$ & $312(152)$ & $320(131)$ & $376(186)$ & $0.001^{\mathrm{a}}$ & \\
\hline \multirow{2}{*}{$\begin{array}{l}\text { Mean hospital stay (SD), } d \\
\text { Number of } 30 \text {-day } \\
\text { complications (\%) }\end{array}$} & $3.54(0.60)$ & $3.58(0.63)$ & $3.6(0.70)$ & $3.52(0.65)$ & $3.69(0.67)$ & 0.531 & \\
\hline & 0 & $17(2.4)$ & $19(3.1)$ & $4(2.5)$ & $4(8.9)$ & 0.129 & \\
\hline
\end{tabular}

${ }^{a}$ Statistically significant difference ( $p<0.05$ ), A: BMI < 18.5; B: BMI 18.5-24.99; C: BMI 25-29.99; D: BMI 30-34.99; E: BMI > 35.

TABle 3: Summary of 30-day complications.

\begin{tabular}{|c|c|c|c|c|c|}
\hline BMI & $<18.5(n=56)$ & $18.5-24.99(n=697)$ & $25-29.99(n=609)$ & $30-34.99(n=158)$ & $>35(n=45)$ \\
\hline Surgery-related (\%) & 0 & $10(58.8)$ & $8(42.1)$ & $2(50)$ & $3(75)$ \\
\hline Surgery-unrelated (\%) & 0 & $7(42.2)$ & $11(57.9)$ & $2(50)$ & $1(25)$ \\
\hline \multicolumn{6}{|c|}{ Complications or readmission related to surgery } \\
\hline Intraoperation fracture & 0 & 4 & 3 & 2 & 1 \\
\hline Sciatic nerve injury & 0 & 1 & 0 & 0 & 0 \\
\hline Superficial wound infection & 0 & 1 & 3 & 0 & 0 \\
\hline Deep infection & 0 & 1 & 0 & 0 & 1 \\
\hline Dislocation & 0 & 3 & 0 & 0 & 0 \\
\hline Stem early subsidence & 0 & 0 & 2 & 0 & 1 \\
\hline \multicolumn{6}{|c|}{ Complications or readmission unrelated to surgery } \\
\hline Fractures due to postoperative fall & 0 & 2 & 3 & 0 & 0 \\
\hline Other medical complications & 0 & $5^{\mathrm{a}}$ & $8^{\mathrm{b}}$ & $2^{\mathrm{c}}$ & $1^{\mathrm{d}}$ \\
\hline
\end{tabular}

${ }^{a} 1$ acute kidney injury, 1 cholecystitis, 1 gastrointestinal bleeding, 1 vertigo, 1 renal insufficiency. ${ }^{\mathrm{b}} 2$ acute myocardial infarction, 3 pneumonia, 1 gastrointestinal bleeding, 1 vertigo, 1 depression. ${ }^{c} 1$ stroke, 1 pneumonia. ${ }^{\mathrm{d}} 1$ acute myocardial infarction.

TABle 4: Multivariate logistic regression analysis identifying independent risk factors for complications within 30 days.

\begin{tabular}{lcc}
\hline Variable & Odds ratio $(95 \% \mathrm{CI})^{\mathrm{a}}$ & $p$ value \\
\hline BMI & Reference & \\
$18-24.99$ & - & - \\
$<18.5$ & $1.12(0.571-2.197)$ & 0.742 \\
$25-29.99$ & $0.762(0.247-2.346)$ & 0.635 \\
$30-34.99$ & $2.415(0.742-7.862)$ & 0.143 \\
$>35$ & $1.027(1.001-1.054)$ & 0.041 \\
Age & $2.443(1.162-5.132)$ & 0.018 \\
Cardiovascular comorbidities & $1.02(1.006-1.034)$ & 0.006 \\
Operative time & & \\
\hline
\end{tabular}

${ }^{\mathrm{a}} \mathrm{CI}$, confidence interval.

[31]. Moreover, obesity increases the likelihood of a number of diseases, including diabetes, cardiovascular disease, obstructive sleep apnea, and cancer, which adds to the complexity of caring for patients undergoing total joint arthroplasty [32, 33]. On the other hand, underweight patients undergoing THAs are also a challenging problem due to their potential osteoporosis and malnutrition status that may incur additional postoperative complications. Understanding the factors associated with perioperative complications and causes of 30-day readmission after primary THA may enable preemptive strategies to mitigate preventable causes for unplanned visits and readmissions [34-37]. The primary aim of this study was to evaluate whether extreme BMI levels are associated with a high incidence of 30- day readmission or major events in patients undergoing primary THA. To our knowledge, this is the largest reported singlesurgeon study of perioperative complications after THA.

Literature regarding the impact of obesity on the occurrence of perioperative complications following THA is abundant. Perioperative complications and readmission rates have been widely reported to be higher in the setting of obese patients undergoing arthroplasty. Some studies have reported an increased risk of postoperative complications among obese patients [38-42]. However, other studies have argued that there are no differences in complication rates [18-20]. A recent meta-analysis of prospective cohort studies reported that obesity negatively influences the overall complication rate, dislocation rate, functional outcome, and operative time of primary THA [14]. Another meta-analysis, including not only prospective studies but also retrospective studies, has reported that obesity appears to have a negative impact on the outcome of total hip replacement procedures [13]. Our study demonstrates that obese patients have a higher risk of perioperative complications after THA (morbidly obese group $8.9 \%$ vs. normal-weight group $2.4 \%$ ). However, there is no significant difference in odds for 30-day complication between those who are morbidly obese and normal-weight patients (Table 4).

There was a trend toward a higher incidence of acute periprosthetic infection in morbidly obese patients $(2.2 \%)$ in our study although these patients represented only $2.9 \%$ of 
those undergoing primary THA. A high rate of infection was previously reported in a meta-analysis evaluating THA in obese patients with a BMI of above $30[13,14]$. Obesity has been reported to be an independent risk factor for periprosthetic infection and all-cause readmission after primary hip arthroplasty [36, 41]. The increased technical difficulty of THA in obese patients requiring longer operative times has also been reported $[43,44]$. The findings of our study showed that the operative time was longer in morbidly obese patients than that in other groups $(p<0.001)$. In addition, increased operative time has been reported to be an independent risk factor for periprosthetic joint infection [44-46] and venous thromboembolism [47] after total joint arthroplasty and remains a potentially modifiable risk factor of interest to orthopedic surgeons. A recent study investigated the effects of operative time on short-term complications after total joint arthroplasty [44]. Operative time $>120$ minutes was associated with increased short-term morbidity and mortality after primary total joint arthroplasty. Moreover, operative time correlated with increased intraoperative blood loss [48, 49]. Hrnack et al. [48] retrospectively analyzed 78 primary THA patients subjected to a mean operative time of 134 minutes and found that increases in operative time were associated with greater intraoperative blood loss. Of particular concern to orthopedic surgeons is the association of obesity with dislocation after primary THAs. Our findings with regard to dislocations following THAs in obese patients differ from previous studies $[13,14]$. There were no significant differences in dislocation rates among different BMI groups. Furthermore, higher surgeon volume was significantly associated with a lower rate of dislocation and deep hip infection [50].

Whether underweight $(\mathrm{BMI}<18.5)$ patients undergoing primary THAs are associated with an increased risk of complications remains the issue of much scrutiny. A low BMI may be the reflection of a state of malnourishment where the body has fewer reserves, cannot react to stress appropriately, and may have a weakened immune system [51]. Musculoskeletal consequences of being underweight include less muscle mass, less soft tissue, and greater probability of osteoporosis [51, 52]. Anoushiravani et al. in a study comparing complications after THAs among underweight and normal BMI patients, demonstrated that underweight patients were more likely to have postoperative cardiac complications [22]. A study by Alfonso et al. demonstrated that a BMI $<18.5 \mathrm{~kg} / \mathrm{m}^{2}$ was associated with significantly increased posterior dislocation and medical complications [21]. In our study, patients with a BMI $<18.5$ undergoing primary THA did not present any complications. Comparison of operation time, blood loss, length of stay, and complications of the underweight group and the normal-weight group showed no difference. As there was a relatively smaller percentage $(3.6 \%, n=1565)$ of the underweight population in our study sample, higher patient numbers are necessary to achieve adequate statistical power to verify this conclusion.

As patients age, the prevalence and severity of comorbid illness are increasing, leading to perioperative complications. In a national database analysis, Boniello et al. [53] compared the rate of 30-day complications and mortality between patients over 80 years of age and under 80 years of age who underwent total hip arthroplasty. They found that "age over 80 years were 1.41 times more likely to sustain complications and 2.02 times more likely to die" than the younger cohort and cardiac comorbidities were independent risk factor for readmission within 30 days. Our result is in accordance with the above database analysis, indicating that advanced age and cardiovascular comorbidities are independent risk factors for perioperative complications after THA.

BMI is one of the most commonly used surrogate markers for evaluating outcomes following surgery, and obesity is an often-cited cause of surgical morbidity [54-57]. Notably, patients with obesity often have an increased incidence of multiple comorbidities including type 2 diabetes, cancer, and cardiovascular diseases [58]. As a result, the utility of BMI alone as a predictor of unfavorable outcomes following THA is under scrutiny. Our study identified more meaningful risk factors that predict unfavorable early outcomes following THA, including advanced age and cardiovascular comorbidities. Based on our findings, we suggest that clinicians avoid using BMI alone for risk assessment for patients undergoing THAs. Instead, our data indicate that advanced age and cardiovascular comorbidities can predict perioperative outcome more accurately.

A potential weakness of this investigation was the fact that complications or readmissions beyond the 30 days after the index surgery were not recorded. Extreme BMI groups, underweight and morbidly obese patients, represent only a small proportion of patients undergoing THA, with only 56 $(3.6 \%)$ and $45(2.9 \%)$ in the underweight patients and morbidly obese patients, respectively. The number of individual complications was not sufficiently large to perform multivariable analysis and identify specific risk factors associated with complications with adequate statistical power. ASA classification has been criticized for their subjective nature [59]. Although this is a single-surgeon series, there were more than 10 anesthesiologists involved in the care of the patients and the criteria for ASA scoring might not be standardized among them. As such, matching patients based on ASA score is less appropriate in our study. Despite these limitations, our study describes the largest single-surgeon cohort of patients undergoing primary THA, eliminating limitations generally encountered by large administrative databases, such as coding accuracy, access to detailed medical records, and different levels of surgical experience.

\section{Conclusion}

We found that patients with $\mathrm{BMI} \geq 35.00 \mathrm{~kg} / \mathrm{m}^{2}$ undergoing THA are associated with longer operative time and more blood loss during procedures, but not with longer hospital stay. The most important finding in our series is that BMI alone does not affect 30-day complications after THA. Moreover, our study does not provide evidence of higher rates of 30-day complications in underweight patients. Operation time, blood loss, and length of hospital stay are comparable to normal-weight patients. Advanced age, 
prolonged operative time, and cardiovascular comorbidities are at increased risk of complications. We should inform patients with above information when undergoing THA. Withholding THA simply on the basis of BMI is not justified.

\section{Data Availability}

The data used to support the findings of this study are available from the corresponding author upon request.

\section{Conflicts of Interest}

All authors state that they have no conflicts of interest.

\section{Acknowledgments}

The authors thank Shu-Ting Gan for the statistical assistance who was supported by the Maintenance Project of the Center for Big Data Analytics and Statistics (grant no. CLRPG3D0045) at Chang Gung Memorial Hospital. The authors also thank Mr Cheng-Hsuan Hsieh who participated in the high school student program in biomedical research at Chang Gung University in 2018, for data collection and review of the literature.

\section{References}

[1] W. H. Harris and C. B. Sledge, "Total hip and total knee replacement," New England Journal of Medicine, vol. 323, no. 11, pp. 725-731, 1990.

[2] O. Ethgen, O. Bruyère, F. Richy, C. Dardennes, and J.-Y. Reginster, "Health-related quality of life in total hip and total knee arthroplasty," The Journal of Bone \& Joint Surgery, vol. 86, no. 5, pp. 963-974, 2004.

[3] I. D. Learmonth, C. Young, and C. Rorabeck, "The operation of the century: total hip replacement," Lancet, vol. 370, no. 9597, pp. 1508-1519, 2007.

[4] S. Kurtz, K. Ong, E. Lau, F. Mowat, and M. Halpern, "Projections of primary and revision hip and knee arthroplasty in the United States from 2005 to 2030," The Journal of Bone and Joint Surgery-American, vol. 89, no. 4, pp. 780-785, 2007.

[5] J. A. Singh, "Epidemiology of knee and hip arthroplasty: a systematic review," The Open Orthopaedics Journal, vol. 5, no. 1, pp. 80-85, 2011.

[6] A. Kumar, W.-C. Tsai, T.-S. Tan, P.-T. Kung, L.-T. Chiu, and M.-C. Ku, "Temporal trends in primary and revision total knee and hip replacement in Taiwan," Journal of the Chinese Medical Association, vol. 78, no. 9, pp. 538-544, 2015.

[7] M. Ng, T. Fleming, M. Robinson et al., "Global, regional, and national prevalence of overweight and obesity in children and adults during 1980-2013: a systematic analysis for the global burden of disease study 2013," Lancet, vol. 384, no. 9945, pp. 766-781, 2014.

[8] E. Vingard, L. Alfredsson, and H. Malchau, "Lifestyle factors and hip arthrosis. A case referent study of body mass index, smoking and hormone therapy in 503 Swedish women," Acta Orthopaedica Scandinavica, vol. 68, no. 3, pp. 216-220, 1997.

[9] A. M. Lievense, "Influence of obesity on the development of osteoarthritis of the hip: a systematic review," Rheumatology, vol. 41, no. 10, pp. 1155-1162, 2002.

[10] L. Jiang, J. Rong, Y. Wang et al., "The relationship between body mass index and hip osteoarthritis: a systematic review and meta-analysis," Joint Bone Spine, vol. 78, no. 2, pp. 150-155, 2011.

[11] C. Reyes, K. M. Leyland, G. Peat, C. Cooper, N. K. Arden, and D. Prieto-Alhambra, "Association between overweight and obesity and risk of clinically diagnosed knee, hip, and hand osteoarthritis: a population-based cohort study," Arthritis \& Rheumatology, vol. 68, no. 8, pp. 1869-1875, 2016.

[12] S. M. Kurtz, K. L. Ong, E. Lau, and K. J. Bozic, "Impact of the economic downturn on total joint replacement demand in the United States," The Journal of Bone and Joint SurgeryAmerican, vol. 96, no. 8, pp. 624-630, 2014.

[13] D. Haverkamp, M. N. Klinkenbijl, M. P. Somford, G. H. R. Albers, and H. M. van der Vis, "Obesity in total hip arthroplasty-does it really matter?," Acta Orthopaedica, vol. 82, no. 4, pp. 417-422, 2011.

[14] W. Liu, T. Wahafu, M. Cheng, T. Cheng, Y. Zhang, and X. Zhang, "The influence of obesity on primary total hip arthroplasty outcomes: a meta-analysis of prospective cohort studies," Orthopaedics \& Traumatology: Surgery \& Research, vol. 101, no. 3, pp. 289-296, 2015.

[15] J. Haynes, D. Nam, and R. L. Barrack, "Obesity in total hip arthroplasty: does it make a difference?," The Bone \& Joint Journal, vol. 99, no. 1, pp. 31-36, 2017.

[16] O. Sadr Azodi, R. Bellocco, K. Eriksson, and J. Adami, "The impact of tobacco use and body mass index on the length of stay in hospital and the risk of post-operative complications among patients undergoing total hip replacement," The Journal of Bone and Joint Surgery, vol. 88, no. 10, pp. 13161320, 2006.

[17] H. M. Kremers, S. L. Visscher, W. K. Kremers, J. M. Naessens, and D. G. Lewallen, "Obesity increases length of stay and direct medical costs in total hip arthroplasty," Clinical Orthopaedics and Related Research, vol. 472, no. 4, pp. 12321239, 2014.

[18] T. Ibrahim, S. Hobson, A. Beiri, and C. N. Esler, "No influence of body mass index on early outcome following total hip arthroplasty," International Orthopaedics, vol. 29, no. 6, pp. 359-361, 2005.

[19] J. R. McLaughlin and K. R. Lee, "The outcome of total hip replacement in obese and non-obese patients at 10- to 18 years," The Journal of Bone and Joint Surgery, vol. 88, no. 10, pp. 1286-1292, 2006.

[20] J. G. Andrew, J. Palan, H. V. Kurup, P. Gibson, D. W. Murray, and D. J. Beard, "Obesity in total hip replacement," The Journal of Bone and Joint Surgery, vol. 90, no. 4, pp. 424-429, 2008.

[21] D. T. Alfonso, R. D. Howell, G. Caceres, P. Kozlowski, and P. E. Di Cesare, "Total hip arthroplasty in the underweight," The Journal of Arthroplasty, vol. 23, no. 7, pp. 956-959, 2008.

[22] A. A. Anoushiravani, Z. Sayeed, M. C. Chambers et al., "Assessing in-hospital outcomes and resource utilization after primary total joint arthroplasty among underweight patients," The Journal of Arthroplasty, vol. 31, no. 7, pp. 1407-1412, 2016.

[23] M. Zusmanovich, B. Kester, J. Feng, and R. Schwarzkopf, "Postoperative complications in underweight patients undergoing total hip arthroplasty: a comparative analysis to normal weight patients," Journal of Orthopaedics, vol. 15, no. 2, pp. 345-348, 2018.

[24] World Health Organization, "Obesity: preventing and managing the global epidemic. Report of a WHO consultation," vol. 894, World Health Organization, Geneva, Switzerland, 2000, WHO Technical Report Series 894.

[25] K. Hardinge, "The direct lateral approach to the hip," The Journal of Bone and Joint Surgery, vol. 64, no. 1, pp. 17-19, 1982. 
[26] P. A. Frndak, T. H. Mallory, and A. V. Lombardi Jr., "Translateral surgical approach to the hip. The abductor muscle split," Clinical Orthopaedics and Related Research, no. 295, pp. 135-141, 1993.

[27] Y. Falck-Ytter, C. W. Francis, N. A. Johanson et al., "Prevention of VTE in orthopedic surgery patients: antithrombotic therapy and prevention of thrombosis, 9th ed: American college of chest physicians evidence-based clinical practice guidelines," Chest, vol. 141, no. 2, pp. e278S-e325S, 2012.

[28] M. Deitel, "Overweight and obesity worldwide now estimated to involve 1.7 billion people," Obesity Surgery, vol. 13, no. 3, pp. 329-330, 2003.

[29] P. T. James, "Obesity: the worldwide epidemic," Clinics in Dermatology, vol. 22, no. 4, pp. 276-280, 2004.

[30] H. C. Chang, H.-C. Yang, H.-Y. Chang et al., "Morbid obesity in Taiwan: prevalence, trends, associated social demographics, and lifestyle factors," PLoS One, vol. 12, no. 2, Article ID e0169577, 2017.

[31] D. Bryan, J. Parvizi, M. Austin et al., "Obesity and total joint arthroplasty: a literature based review," The Journal of Arthroplasty, vol. 28, no. 5, pp. 714-721, 2013.

[32] R. T. Hurt, C. Kulisek, L. A. Buchanan, and S. A. McClave, "The obesity epidemic: challenges, health initiatives, and implications for gastroenterologists," Gastroenterol Hepatol, vol. 6, no. 12, pp. 780-792, 2010.

[33] P. F. Bergin and G. V. Russell, "The effects of obesity in orthopaedic care," Instructional Course Lectures, vol. 64, pp. 11-24, 2015.

[34] S. F. Jencks, M. V. Williams, and E. A. Coleman, "Rehospitalizations among patients in the medicare fee-for-service program," New England Journal of Medicine, vol. 360, no. 14, pp. 1418-1428, 2009.

[35] J. A. Bosco 3rd, A. J. Karkenny, L. H. Hutzler, J. D. Slover, and R. Iorio, "Cost burden of 30-day readmissions following medicare total hip and knee arthroplasty," The Journal of Arthroplasty, vol. 29, no. 5, pp. 903-905, 2014.

[36] A. M. Ali, M. D. Loeffler, P. Aylin, and A. Bottle, "Factors associated with 30-day readmission after primary total hip arthroplasty: analysis of 514455 procedures in the UK national health service," JAMA Surgery, vol. 152, no. 12, Article ID e173949, 2017.

[37] U. S. Sibia, A. E. Mandelblatt, M. A. Callanan, J. H. MacDonald, and P. J. King, "Incidence, risk factors, and costs for hospital returns after total joint arthroplasties," The Journal of Arthroplasty, vol. 32, no. 2, pp. 381-385, 2017.

[38] R. S. Namba, L. Paxton, D. C. Fithian, and M. L. Stone, "Obesity and perioperative morbidity in total hip and total knee arthroplasty patients," The Journal of Arthroplasty, vol. 20, no. 7, pp. 46-50, 2005.

[39] A. Lubbeke, R. Stern, G. Garavaglia, L. Zurcher, and P. Hoffmeyer, "Differences in outcomes of obese women and men undergoing primary total hip arthroplasty," Arthritis \& Rheumatism, vol. 57, no. 2, pp. 327-334, 2007.

[40] V. P. Patel, M. Walsh, B. Sehgal, C. Preston, H. DeWal, and P. E. Di Cesare, "Factors associated with prolonged wound drainage after primary total hip and knee arthroplasty," The Journal of Bone and Joint Surgery-American, vol. 89, no. 1, pp. 33-38, 2007.

[41] M. M. Dowsey and P. F. Choong, "Obesity is a major risk factor for prosthetic infection after primary hip arthroplasty," Clinical Orthopaedics and Related Research, vol. 466, no. 1, pp. 153-158, 2008.
[42] Y. H. Chee, K. H. Teoh, B. M. Sabnis, J. A. Ballantyne, and I. J. Brenkel, "Total hip replacement in morbidly obese patients with osteoarthritis: results of a prospectively matched study," The Journal of Bone and Joint Surgery, vol. 92, no. 8, pp. 1066-1071, 2010.

[43] P. K. Michalka, R. J. K. Khan, M. C. Scaddan, S. Haebich, N. Chirodian, and J. A. Wimhurst, "The influence of obesity on early outcomes in primary hip arthroplasty," The Journal of Arthroplasty, vol. 27, no. 3, pp. 391-396, 2012.

[44] K. R. Duchman, A. J. Pugely, C. T. Martin, Y. Gao, N. A. Bedard, and J. J. Callaghan, "Operative time affects short-term complications in total joint arthroplasty," The Journal of Arthroplasty, vol. 32, no. 4, pp. 1285-1291, 2017.

[45] R. H. Fitzgerald Jr., D. R. Nolan, D. M. Ilstrup, R. E. Van Scoy, J. A. Washington, and M. B. Coventry, "Deep wound sepsis following total hip arthroplasty," The Journal of Bone \& Joint Surgery, vol. 59, no. 7, pp. 847-855, 1977.

[46] K. Saleh, M. Olson, S. Resig et al., "Predictors of wound infection in hip and knee joint replacement: results from a 20 year surveillance program," Journal of Orthopaedic Research, vol. 20, no. 3, pp. 506-515, 2002.

[47] A. K. Jaffer, W. K. Barsoum, V. Krebs, J. G. Hurbanek, N. Morra, and D. J. Brotman, "Duration of anesthesia and venous thromboembolism after hip and knee arthroplasty," Mayo Clinic Proceedings, vol. 80, no. 6, pp. 732-738, 2005.

[48] S. A. Hrnack, N. Skeen, T. Xu, and A. D. Rosenstein, "Correlation of body mass index and blood loss during total knee and total hip arthroplasty," American Journal of Orthopedics, vol. 41, no. 10, pp. 467-471, 2012.

[49] N. B. Frisch, N. M. Wessell, M. A. Charters, S. Yu, J. J. Jeffries, and C. D. Silverton, "Predictors and complications of blood transfusion in total hip and knee arthroplasty," The Journal of Arthroplasty, vol. 29, no. 9, pp. 189-192, 2014.

[50] J. N. Katz, E. Losina, J. Barrett et al., "Association between hospital and surgeon procedure volume and outcomes of total hip replacement in the United States medicare population," The Journal of Bone and Joint Surgery-American, vol. 83, no. 11, pp. 1622-1629, 2001.

[51] G. P. Buzby, J. L. Mullen, D. C. Matthews, C. L. Hobbs, and E. F. Rosato, "Prognostic nutritional index in gastrointestinal surgery," The American Journal of Surgery, vol. 139, no. 1, pp. 160-167, 1980.

[52] D. L. Broussard and J. H. Magnus, "Risk assessment and screening for low bone mineral density in a multi-ethnic population of women and men: does one approach fit all?," Osteoporosis International, vol. 15, no. 5, pp. 349-360, 2004.

[53] A. J. Boniello, M. S. Simon, C. C. Emenari, and P. M. Courtney, "Complications and mortality following total hip arthroplasty in the octogenarians: an analysis of a national database," The Journal of Arthroplasty, vol. 33, no. 7, pp. S167-S171, 2018.

[54] S. D. Akinleye, G. Garofolo, M. D. Culbertson, P. Homel, and O. Erez, "The role of BMI in hip fracture surgery," Geriatric Orthopaedic Surgery \& Rehabilitation, vol. 9, Article ID 2151458517747414, 2018.

[55] J. R. Foran, M. A. Mont, G. Etienne, L. C. Jones, and D. S. Hungerford, "The outcome of total knee arthroplasty in obese patients," Journal of Bone and Joint Surgery, vol. 86, no. 8, pp. 1609-1615, 2004.

[56] R. J. Friedman, S. Hess, S. D. Berkowitz, and M. Homering, "Complication rates after hip or knee arthroplasty in morbidly obese patients," Clinical Orthopaedics and Related Research, vol. 471, pp. 3358-3366, 2013. 
[57] E. J. Golan, J. D. Tolla, M. D. Culbertson-Scott, R. Krochak, and J. Choueka, "Obesity is not a predictor of complications in upper extremity surgery," HAND, vol. 14, no. 2, pp. 264-270, 2019.

[58] D. W. Haslam and W. P. James, “Obesity," Lancet, vol. 366, no. 9492, pp. 1197-1209, 2005.

[59] D. Mayhew, V. Mendonca, and B. V. S. Murthy, "A review of ASA physical status-historical perspectives and modern developments," Anaesthesia, vol. 74, no. 3, pp. 373-379, 2019. 


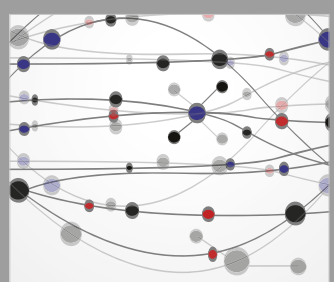

The Scientific World Journal
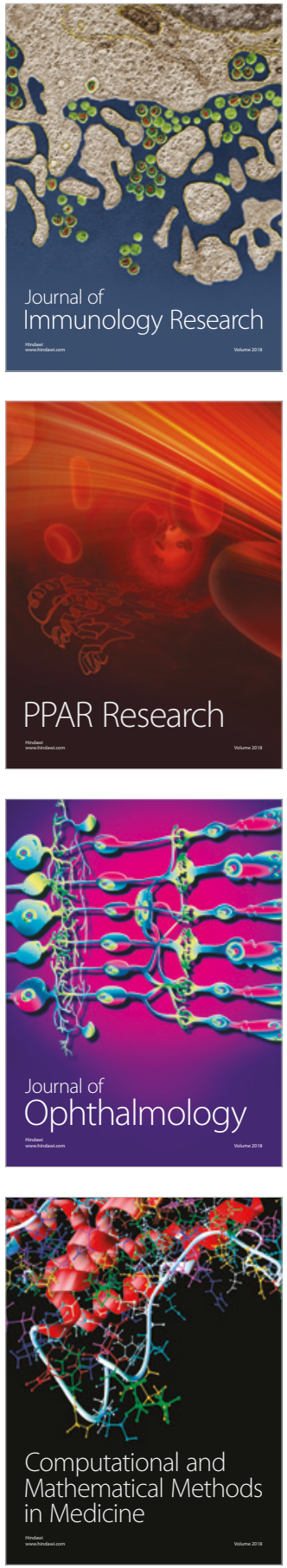

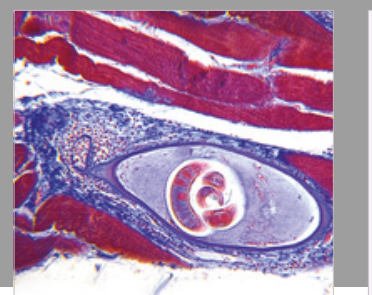

Gastroenterology Research and Practice

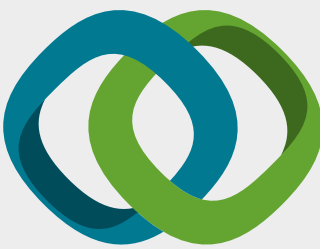

\section{Hindawi}

Submit your manuscripts at

www.hindawi.com
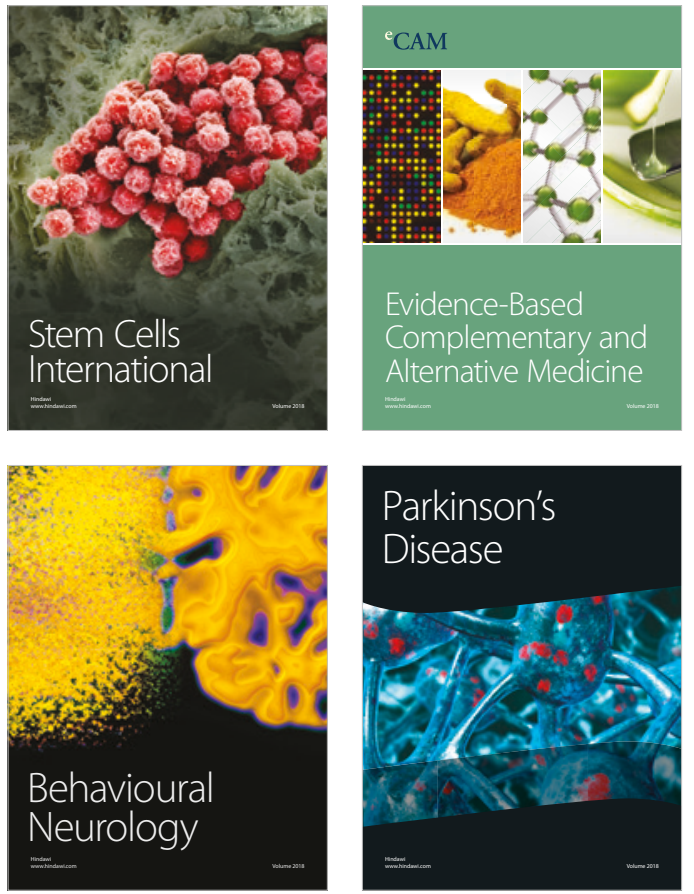

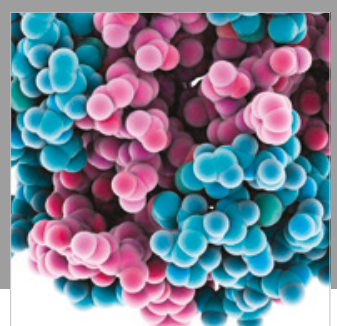

ournal of

Diabetes Research

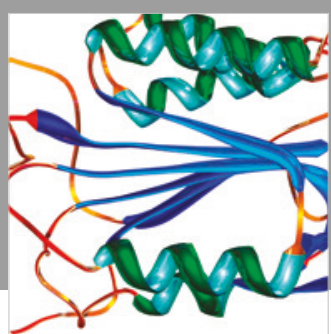

Disease Markers
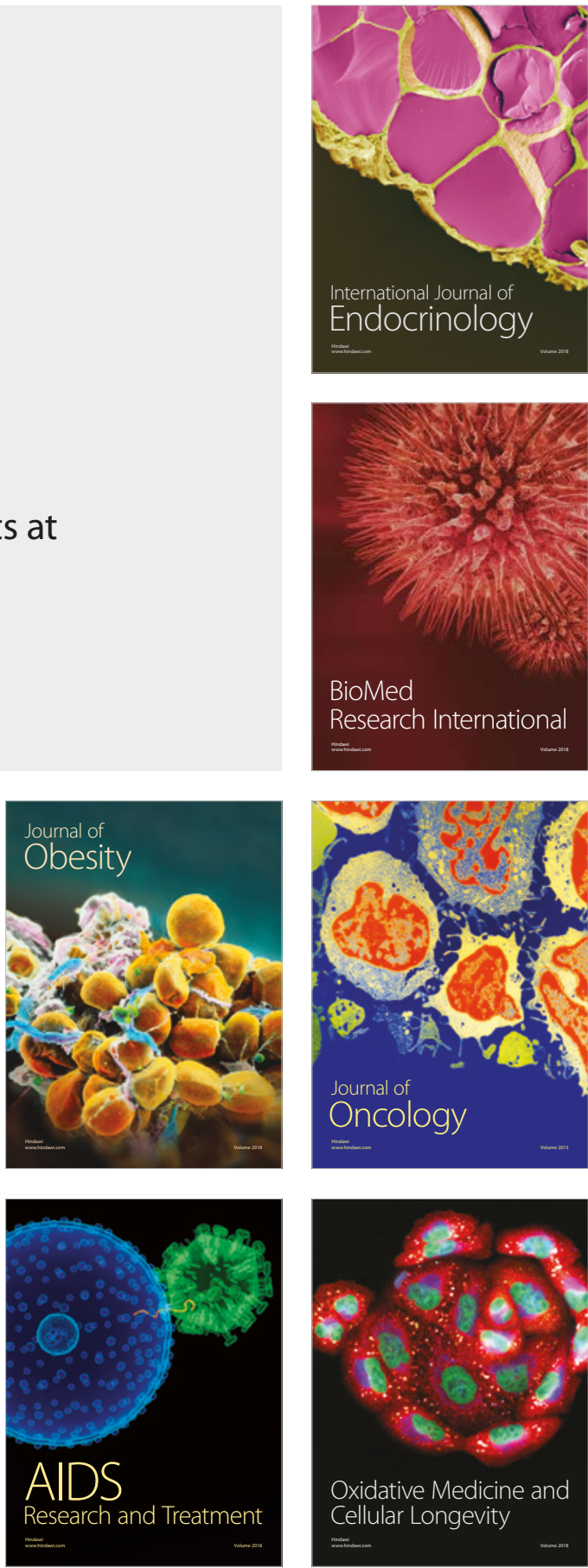